\title{
Imaging Features of Midface Injectable Fillers and Associated Complications
}

D.T. Ginat and C.J. Schatz

\begin{abstract}
SUMMARY: Injectable fillers are increasingly used for midface augmentation, which can be performed for facial rejuvenation and treatment of HIV facial lipoatrophy. A variety of temporary and permanent filler agents has been developed, including calcium hydroxylapatite, collagen, liquid silicone, polytetrafluoroethylene, hyaluronic acid, poly-L-lactic acid, and polyacrylamide gel. Facial fillers are sometimes encountered on radiologic imaging incidentally and should not be mistaken for pathology. Alternatively, patients with facial fillers may undergo imaging specifically to evaluate associated complications, such as infection, overfilling, migration, foreign-body reaction, and scarring. Therefore, it is important to be familiar with the imaging appearances of the various filler materials and their complications.
\end{abstract}

$\mathbf{F}_{\mathrm{i}, \mathrm{s}}$ llowing the invention of the syringe in the late 19th century, injection of chemical agents was performed for facial augmentation. ${ }^{1}$ Perhaps the first substance used as a facial filler agent was paraffin, which was abandoned once significant complications such as migration, embolization, and granuloma formation were noted. ${ }^{1}$ In recent years, many products have been developed and approved for use as dermal and subdermal injectable fillers for facial rejuvenation. These treatments have been increasing in popularity because they yield desirable esthetic outcomes without invasive surgical procedures. As a result, it is not uncommon to encounter facial fillers on imaging studies, either incidentally or for evaluating an associated complication. Therefore, it is important for the radiologist to be familiar with the imaging features of commonly used injectable fillers and to avoid confounding these with true pathology.

\section{CALCIUM HYDROXYLAPATITE}

Injectable calcium hydroxylapatite (Radiesse) has been FDA- approved since December 2006 for the treatment of facial lipoatrophy and wrinkles. ${ }^{2}$ The product consists of microspheres of calcium hydroxylapatite suspended in a methylcellulose gel matrix. ${ }^{2}$

From the Department of Radiology (D.T.G.), Massachusetts General Hospital, Harvard Medical School, Boston, Massachusetts; and Department of Radiology (C.J.S.), Beverly Tower Wilshire Advanced Imaging, University of Southern California Keck School of Medicine, Los Angeles, California.

Please address correspondence to Daniel T. Ginat, MD, MS, 55 Fruit St, Boston, MA 02114; e-mail: ginatd01@gmail.com

-- Indicates open access to non-subscribers at www.ajnr.org

http://dx.doi.org/10.3174/ajnr.A3161
The filler appears as high-attenuation linear streaks or clumps on CT, with attenuation values typically in the range of range 280$700 \mathrm{HU}$ and appears on MR imaging as low-to-intermediate signal intensity on both T1- and T2-weighted sequences (Fig 1). ${ }^{3-5}$ In addition, the material appears as hypermetabolic on FDGPET due to attenuation-correction artifacts (Fig 2). Calcium hydroxylapatite fillers gradually resorb, lasting $\geq 2$ years. ${ }^{2}$ Local inflammation surrounding the calcium hydroxyapatite sometimes occurs during the first week. The agent is generally not injected around the lips due to a tendency to form clumps in this area. Otherwise, long-term or delayed-onset adverse events are rare. ${ }^{6}$

\section{COLLAGEN AND COLLAGEN MIXED WITH POLYMETHYLMETHACRYLATE}

Collagen fillers (Evolence, Permacol, CosmoPlast, Autologen, Dermicol, Dermologen, Cymetra, Zyderm, Zyplast) are based on naturally occurring protein derived from a variety of sources. ${ }^{7-10}$ Bovine collagen has been FDA-approved since 1981 for treating scars, lines, and wrinkles, while porcine collagen has been FDA-approved since June 2008. Collagen can be mixed with polymethylmethacrylate microspheres (Artefill). In addition, autologous and allogeneic human tissue collagen matrix fillers have been used. On CT, collagen fillers approximately display fluid attenuation, and the surrounding subcutaneous fat appears infiltrated. On MR imaging, collagen fillers are low signal on T1and high signal on T2-weighted sequences (Fig 3). There can also be minimal peripheral enhancement that persists up to 2 months. The filler itself lasts approximately 6-12 months. 

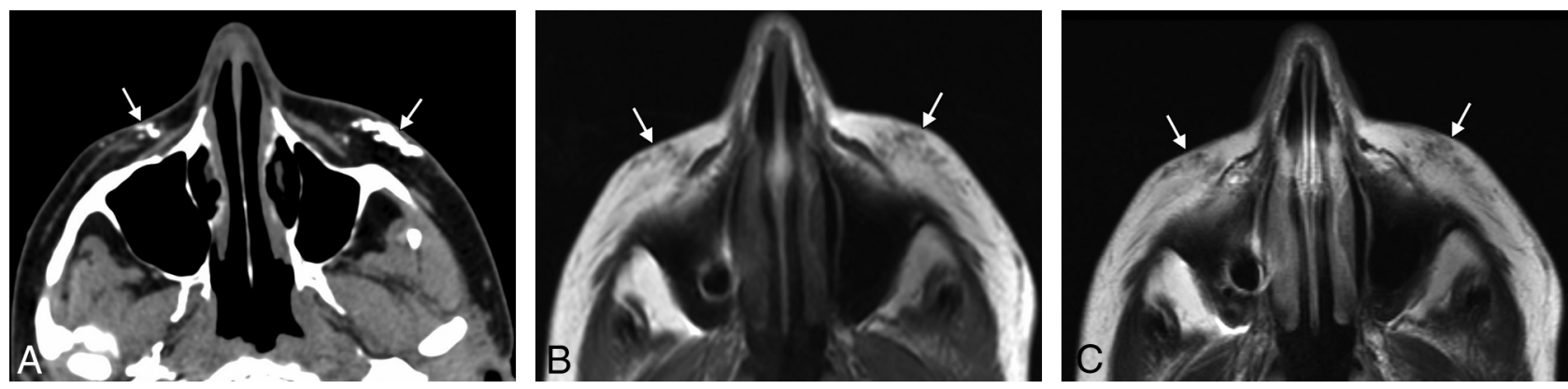

FIG 1. Calcium hydroxyapatite. Axial CT image $(A)$ shows hyperattenuated material within the bilateral cheek subcutaneous tissues (arrows). Axial T1 (B) and T2 (C) MR images show that the fillers have low-to-intermediate signal on both sequences (arrows).

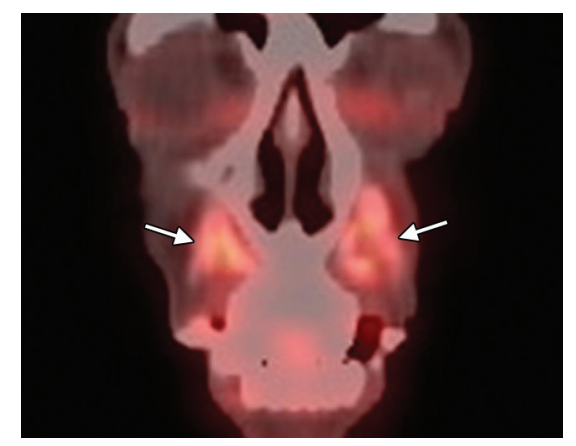

FIG 2. Calcium hydroxyapatite. Coronal ${ }^{18}$ FDG-PET image shows apparent hypermetabolism at the site of the fillers, which can be a false-positive finding for malignant disease (arrows).

\section{LIQUID SILICONE}

Liquid silicone (polydimethylsiloxane; Silikon, AdatoSil) or silicone oil is a synthetic permanent agent that has been used for facial augmentation and treatment of acne scars for $>50$ years. ${ }^{11}$ On CT, liquid silicone appears to have similar or slightly higher attenuation than soft tissue (Fig 4). Silicone oil tends to be hyperintense to water on $\mathrm{T} 1$ and isointense to hypointense to water on T2. ${ }^{12}$ Higher viscosity oils tend to be hypointense on a T2weighted image compared with lower viscosity oils. ${ }^{12}$ Chemical shift artifacts and fat suppression can also be noted. Complications related to the use of silicone oil facial injection are relatively frequent and potentially severe and irreparable, particularly with high volumes of impure industrial or nonmedical grades, lowviscosity silicone, poor injection technique, and/or concomitant disease. $^{1,13}$

\section{POLYTETRAFLUOROETHYLENE}

Expanded polytetrafluoroethylene (Gore-Tex) has been FDA-approved for facial augmentation since the mid-1990s, particularly in the lips, nasolabial folds, and glabella. ${ }^{14,15}$ The material is permanent but inert with a highly porous structure and can be intro-
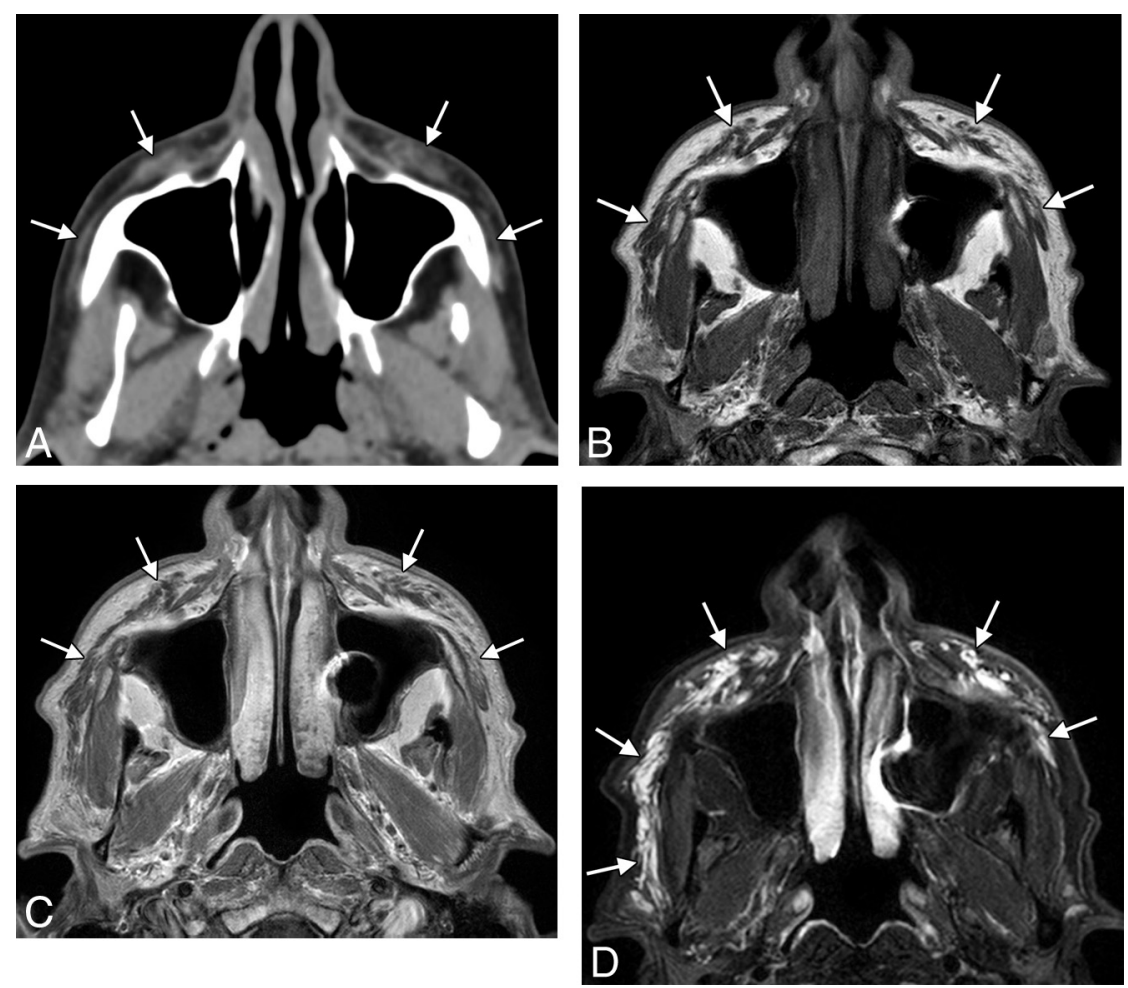

FIG 3. Collagen. Axial CT image $(A)$ shows stranding in the bilateral cheek subcutaneous tissues (arrows). Axial $\mathrm{Tl}(B)$, postcontrast $\mathrm{Tl}(C)$, and fat-saturated T2 (D) MR images show that the filler has nearly fluid signal characteristics (arrows). 

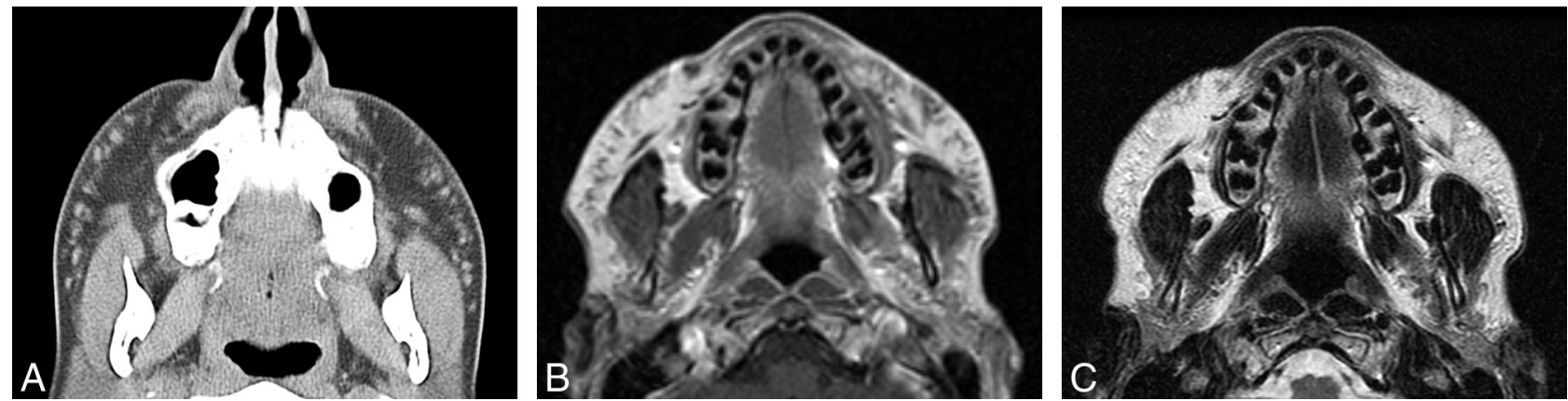

FIG 4. Liquid silicone. Axial CT image (A) shows numerous high-attenuation foci within the bilateral cheeks (arrows). Axial Tl (B) and T2 (C) MR images show corresponding intermediate signal on both sequences.

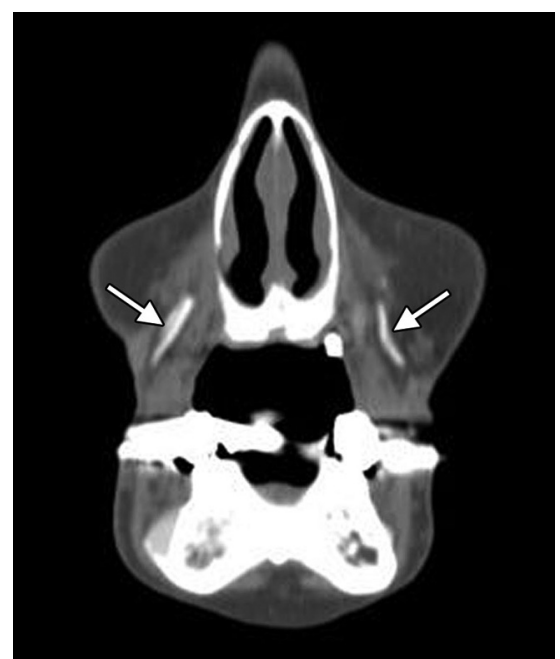

FIG 5. Polytetrafluoroethylene. Coronal CT image shows linear hyperattenuation in the bilateral nasolabial folds (arrows).

duced via small needles in the form of threads or inserted via microincisions. Some Gore-Tex fillers have tubular configurations to promote tissue in-growth. Gore-Tex displays attenuation in the range of 300-400 $\mathrm{HU}$ on CT (Fig 5) and a low signal with respect to fat on $\mathrm{T} 1$ - and $\mathrm{T} 2$-weighted $\mathrm{MR}$ imaging sequences. ${ }^{3,16}$

\section{HYALURONIC ACID}

Hyaluronic acid-based gel fillers (Restylane, Perlane, Juvéderm) are biocompatible, biodegradable, nonpermanent fillers used for both facial rejuvenation and HIV lipoatrophy. ${ }^{17-19}$ The various brands have different concentrations of hyaluronic acid and cross-linking chemistries, which impart different viscosities. The more viscous forms of hyaluronic acid gel are appropriate for treating HIV lipoatrophy, while the soft and pliable consistency of the less viscous forms is particularly suitable for use in the lips, perioral, and periocular regions. ${ }^{18}$ On CT, hyaluronic acid fillers demonstrate nearly fluid attenuation and the surrounding subcutaneous fat can appear infiltrated. Hyaluronic acid has a T2 relaxation time of approximately $600 \mathrm{~ms}$, which is much higher than that for dermal and subdermal tissues. Indeed, hyaluronic acid gel fillers have an MR imaging appearance similar to that of water (Fig 6). In addition, the progressive diffusion and degradation of the filler can be observed over serial MRIs. ${ }^{20}$ On postcontrast T1-weighted sequences, there is occasionally minimal peripheral enhancement that can last up to 2 months. In general, hyaluronic acid has a lower incidence of complications than semipermanent and permanent agents. ${ }^{19}$ Furthermore, hyaluronic acid fillers can be rapidly reversed by injection of hyaluronidase. ${ }^{19,21}$

\section{POLY-L-LACTIC ACID}

Poly-L-lactic acid (Sculptra) is a synthetic biodegradable polymer that received FDA approval in August 2004 for treatment of facial lipoatrophy in patients with HIV, but it is also used for facial rejuvenation. ${ }^{22,23}$ The polymer is derived from corn starch and is prepared in a solution of mannitol and carbomethoxycellulose. The filler is biostimulatory and promotes collagen formation, which results in a gradual increase in dermal volume. ${ }^{24}$ On CT, poly-L-lactic acid appears as soft-tissue attenuation foci sur-
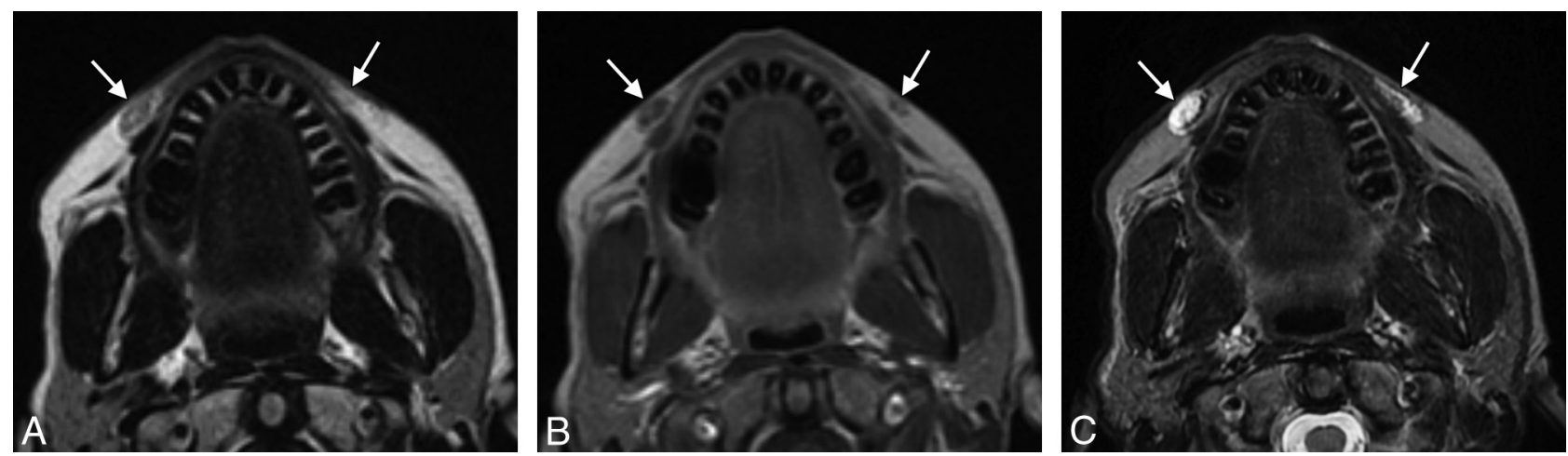

FIG 6. Hyaluronic acid gel. Axial $\mathrm{Tl}(A)$ and fat-suppressed postcontrast $\mathrm{Tl}(B)$ and $\mathrm{T} 2(C)$ MR images show bilateral fluid-intensity collections in the nasolabial folds, right greater than left (arrows). 


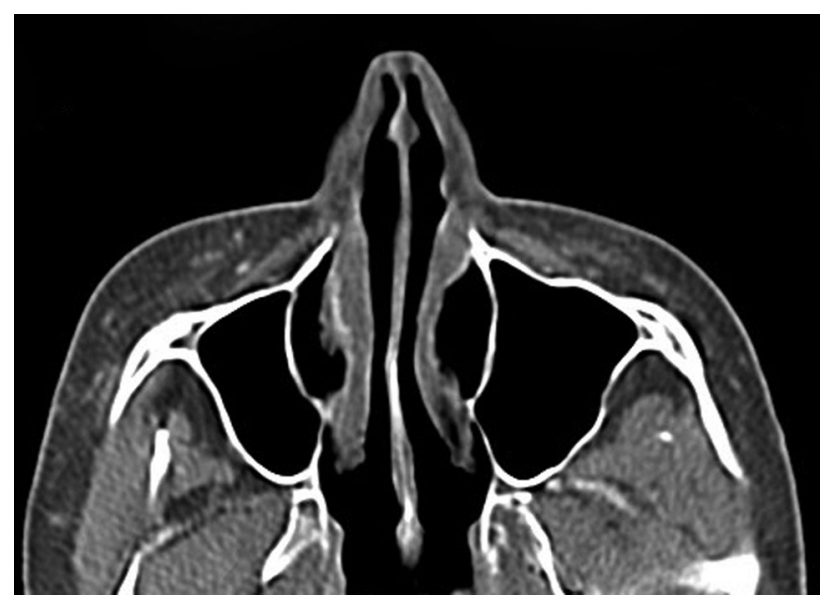

FIG 7. Poly-L-lactic acid. Axial CT image shows bilateral irregular softtissue attenuation, with surrounding stranding in the subcutaneous tissues of the cheeks.

rounded by stranding of the subcutaneous fat that may represent collagen formation (Fig 7).

\section{POLYACRYLAMIDE GEL}

Polyacrylamide (Bio-Alcamid) is formed from polymerization of acrylamide monomers. Polyacrylamide gel contains $2.5 \%-5 \%$ of polyacrylamide suspended in 95\%-97.5\% water and is biocompatible. ${ }^{25}$ Due to the high water content, polyacrylamide gel displays high signal intensity on T2-weighted images and low signal intensity on T1-weighted images, ${ }^{3}$ similar to that of water on MR imaging (Fig 8). Thus, polyacrylamide gel is best depicted by using a T2-weighted MR imaging with or without fat suppression to delineate its location and extent. A thin low T2 signal rim surrounding the collections of polyacrylamide gel is commonly identified and likely corresponds to fibrous capsules found at open surgery. ${ }^{25}$

\section{COMPLICATIONS}

All facial fillers can cause both early and late complications. Early complications (days to weeks after injection) include immediate hypersensitivity reaction, overcorrection, infection, skin necrosis, and discoloration. ${ }^{26}$ Late complications (weeks to years after injection) include infection, filler migration, delayed hypersensitivity reaction, foreign-body granuloma, and scarring. ${ }^{26}$ Imaging with CT and/or MR is warranted for evaluating many of these complications.

Because there is some degree of skin trauma incurred during facial-filler injections, micro-organisms can be introduced into the dermal tissues. The incidence of infections appears to be low if the procedure is performed in an appropriate setting with proper sterile technique. For example, infections were reported in $0.2 \%$ of cases in a series of $>1300$ patients treated with polyacrylamide injections. ${ }^{27}$ Staphylococcus aureus is the most common organism responsible for facial filler infections, though there is also an increased incidence of mycobacterial infections with cosmetic fillers. ${ }^{26}$ On imaging, infection in the form of cellulitis can appear as
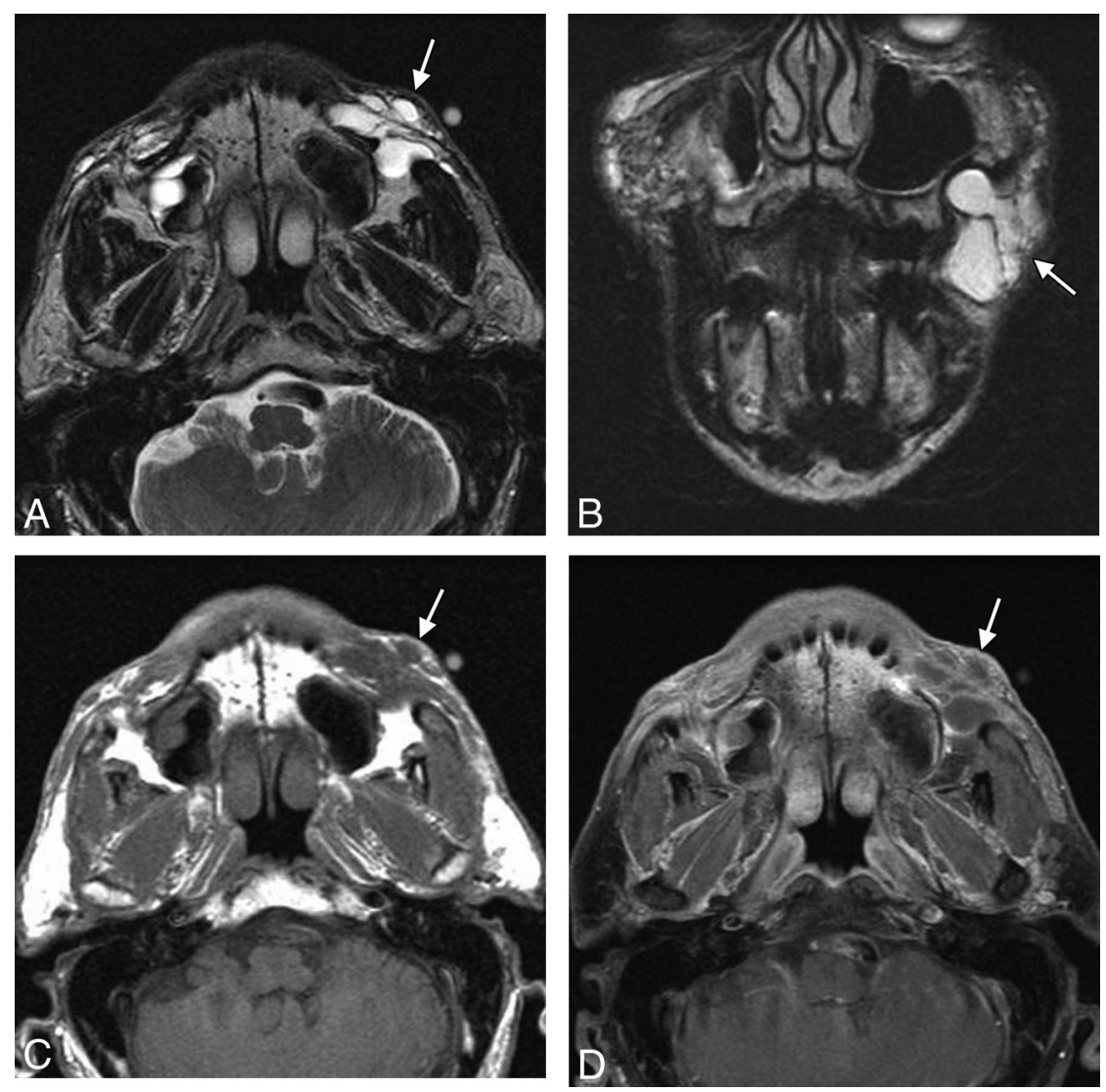

FIG 8. Polyacrylamide gel. Axial $\mathrm{Tl}(A)$ and $\mathrm{T} 2(B)$ MR images show a cluster of fluid-intensity collections surrounded by thin hypointense capsules within the left buccal space (arrows). 

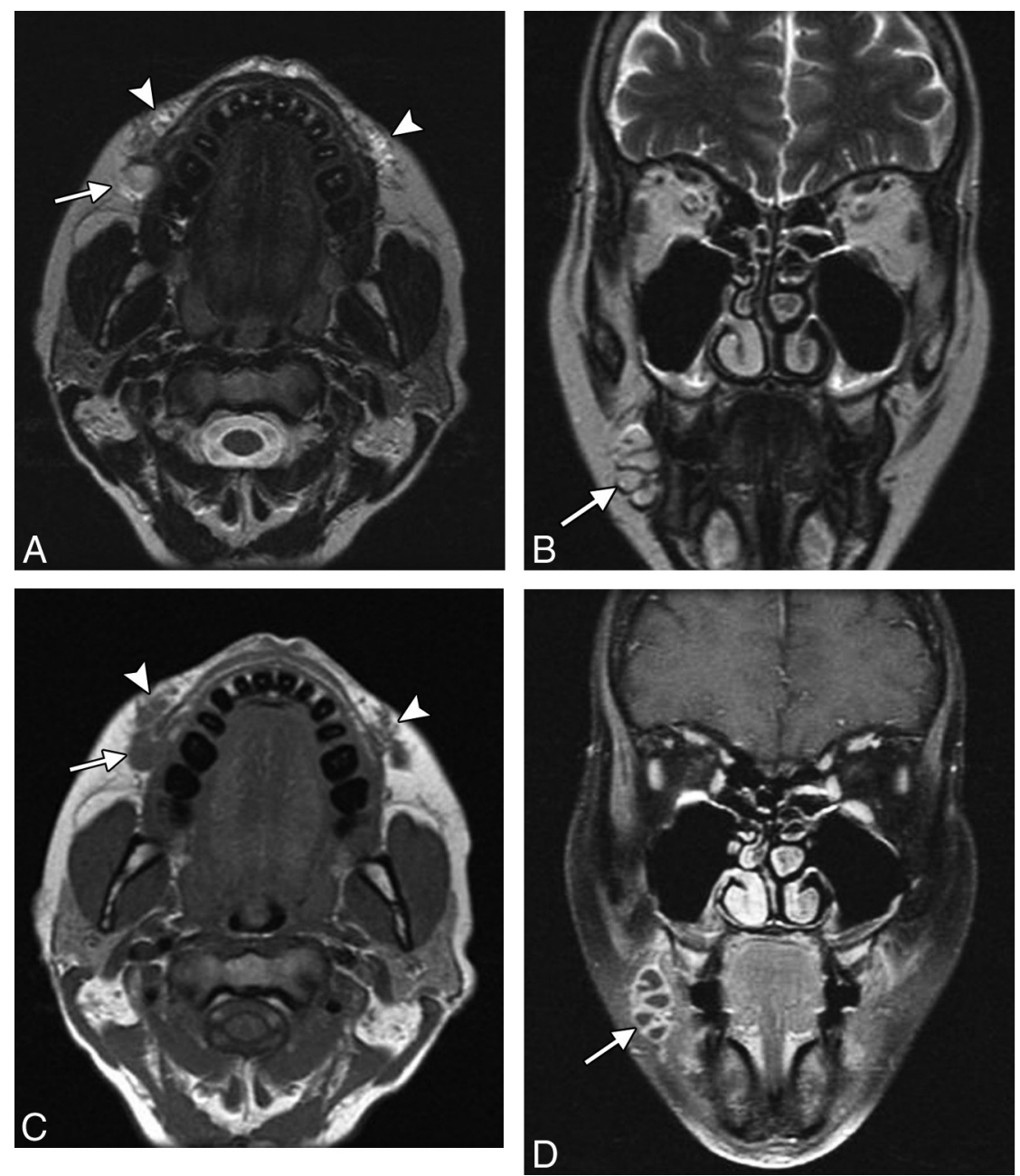

FIG 9. Abscess. The patient presented with painful swelling of right cheek after hyaluronic acid injection 2 months earlier. Axial ( $A$ ) and coronal (B) T2, axial T (C), and coronal fat-saturated postcontrast T1 (D) MR images show deposits of hyaluronic acid in the bilateral oral commissures and upper lip (arrowheads). Posterior to the filler on the right, there is a multiloculated rim-enhancing fluid collection (arrows).
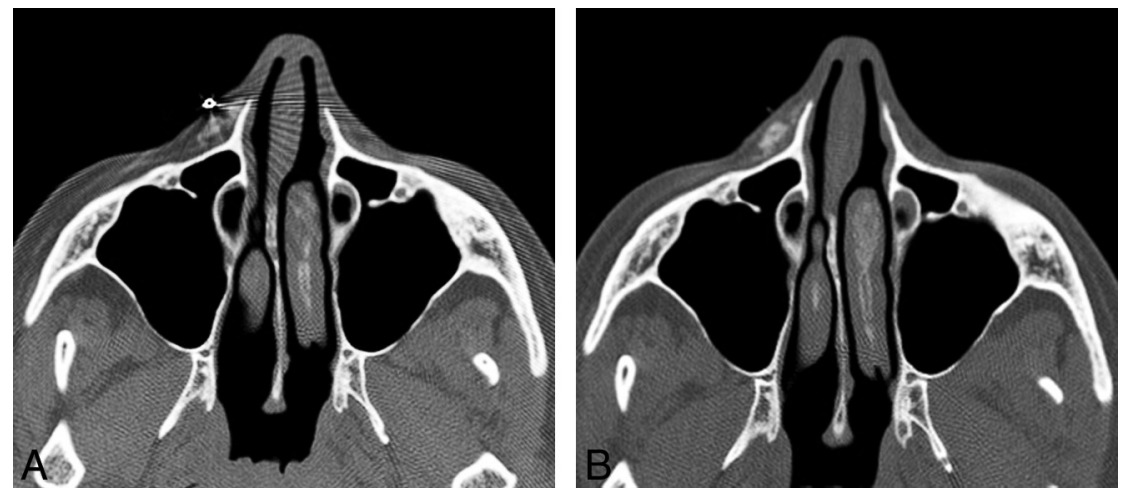

FIG 10. Overfilling. The patient presented with a facial lump and did not initially disclose a history of facial augmentation, which prompted imaging evaluation. A metallic marker was placed over the affected site. Axial CT images ( $A$ and $B)$ show asymmetric contour deformity of the right nasolabial fold where there is a prominent deposit of filler agent. Courtesy of Gul Moonis, MD.

stranding and enhancement of the subcutaneous tissues in the vicinity of the filler, resembling inflammatory reactions, or as rim-enhancing collections if abscesses develop (Fig 9). Abscess can be difficult to differentiate from focal deposits of filler materials such as hyaluronic acid, which resembles fluid on CT and MR imaging. However, abscesses tend to display a greater degree of surrounding enhancement.
Overfilling (overcorrection) consists of injecting excess filler agent, which can lead to lumpiness and conspicuity of the material under the skin surface and patient dissatisfaction. This complication occurs in $0.2 \%-8 \%$ of cases. ${ }^{28}$ Imaging can be useful for delineating the extent of the excess material, which can be identified by contour deformity of the overlying skin (Fig 10). Patients who present for imaging evaluation of skin bulges may be reluc- 

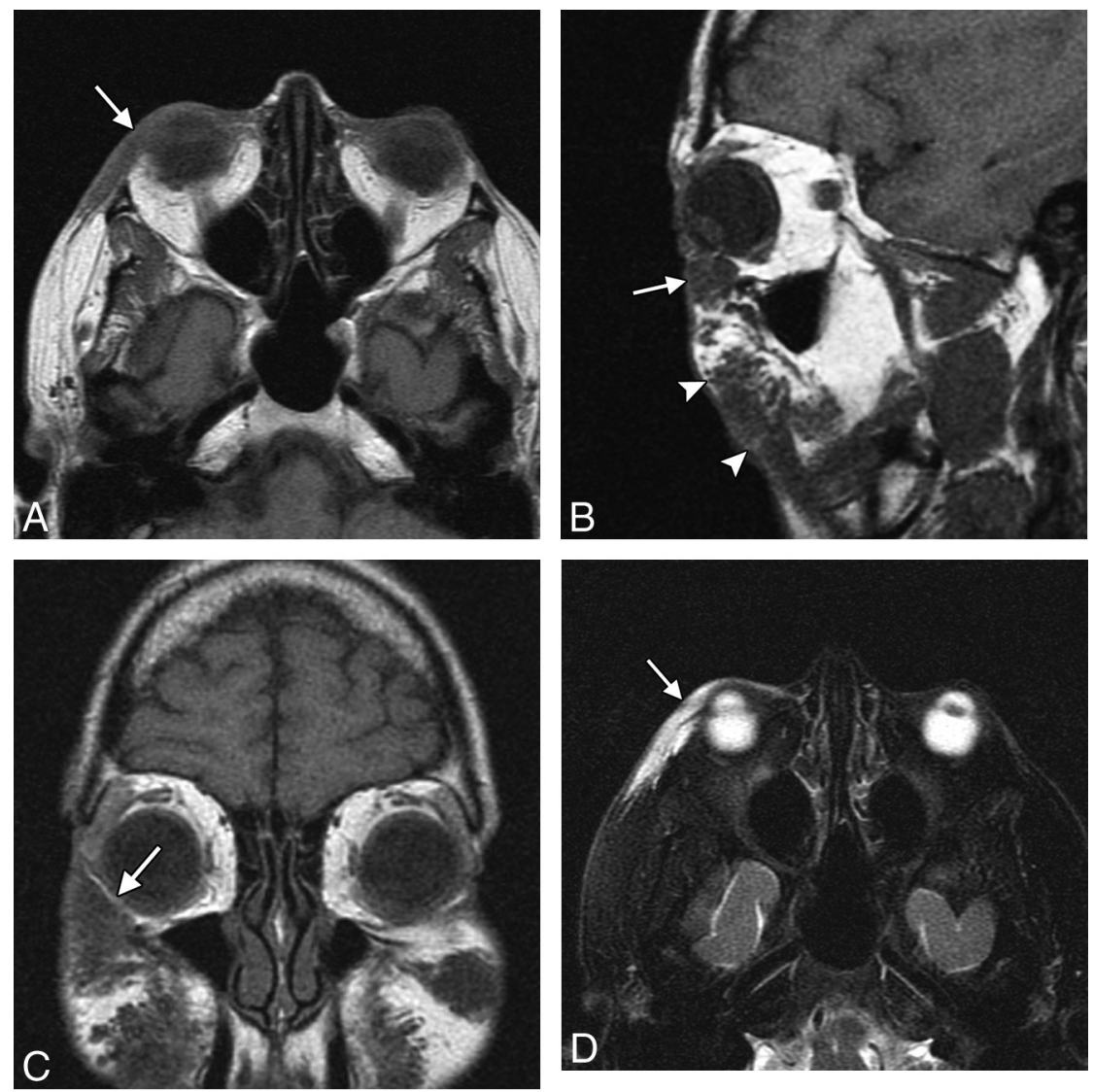

FIG 11. Migration. The patient presented with an eyelid "mass" after hyaluronic acid injection in the cheeks. Axial ( $A$ ), sagittal (B), and coronal (C) $\mathrm{T1}$ and axial fat-suppressed T2 (D) MR images show a globular collection of hyaluronic acid within the inferior eyelid (arrow), which extends superiorly from large deposits of filler in the cheeks (arrowheads).
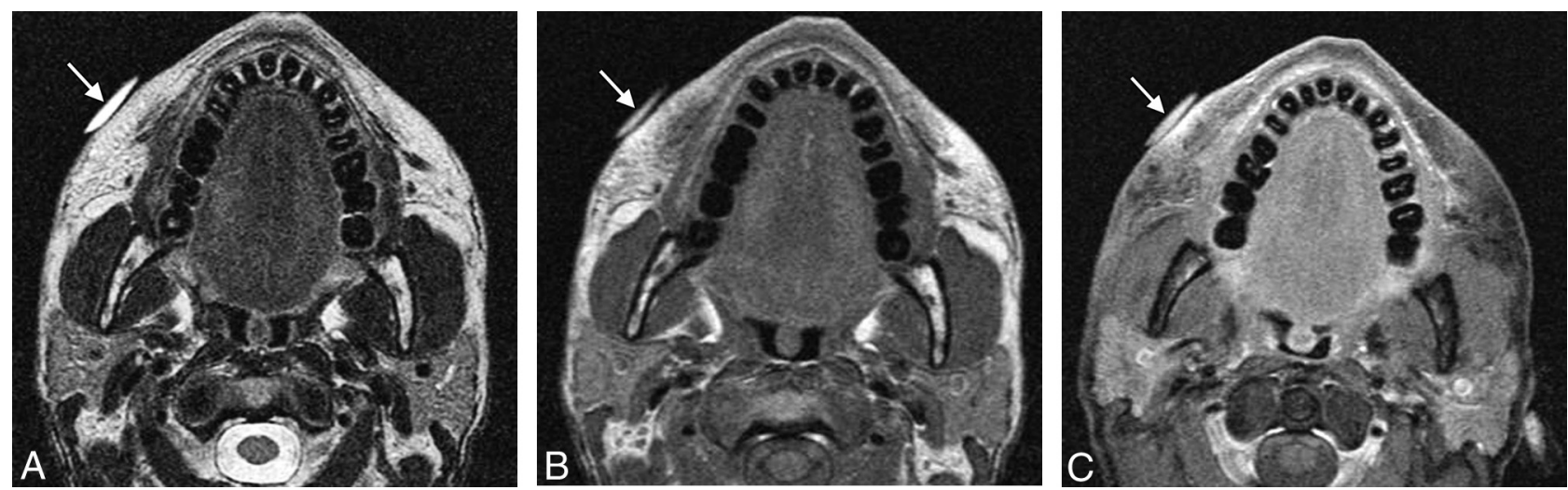

FIG 12. Chronic inflammation. The patient presented with right-greater-than-left facial swelling approximately 5 years after silicone injection. Axial T2 $(A), T 1(B)$, and fat-saturated postcontrast $\mathrm{Tl}(C)$ MR images show an external marker overlying the lower right cheek (arrows), where there is diffuse swelling and enhancement surrounding the filler material. Milder involvement is also noted in the left side.

tant to disclose a history of facial augmentation, making the diagnosis somewhat less straightforward. Nevertheless, if material with any of the imaging characteristics described in the previous sections is identified at the affected site, overfilling should be included in the differential diagnosis. Conversely, what appears to be an asymmetric distribution of filler agent on imaging does not imply that the patient is necessarily displeased with the cosmetic outcome. Overfilling can be treated via needle aspiration, hyaluronidase in the case of hyaluronic acid, or surgical excision of permanent fillers.

Filler migration consists of spontaneous displacement of the material away from the intended site of injection and has been reported to occur in $3 \%$ of cases with polyacrylamide. ${ }^{27}$ This complication is not only cosmetically displeasing but can be uncomfortable and debilitating, particularly if the filler migrates to sensitive areas such as the eyelids (Fig 11). The use of smaller droplets of filler material tends to decrease the risk of migration. Treatment options include local corticosteroid injections, hyaluronidase injection for hyaluronic acid, or removal of the filler.

A mild degree of inflammation occurs with most fillers and is usually transient. ${ }^{29}$ However, filler agents can occasionally elicit a more severe chronic inflammatory response within the subcuta- 


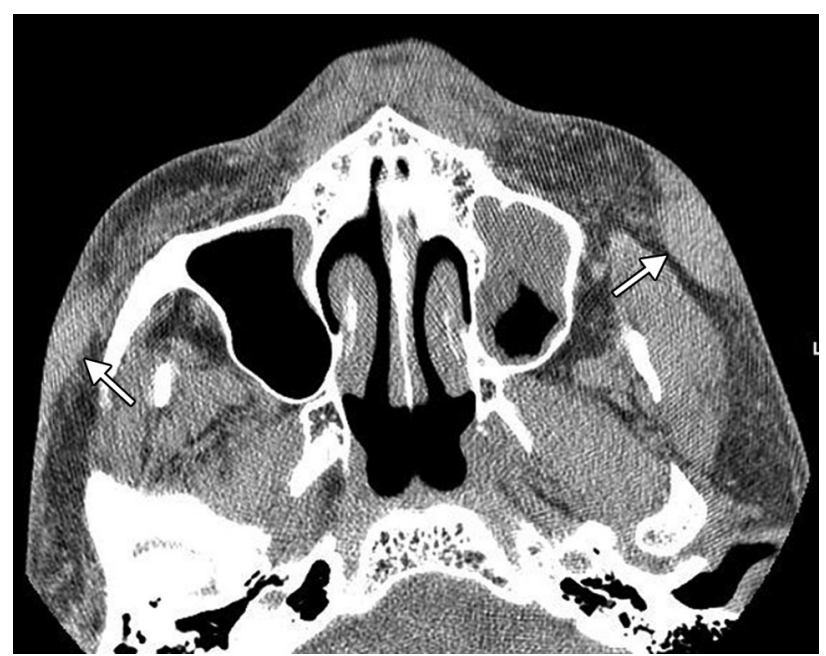

FIG 13. Scarring. The patient has a remote history of liquid silicone injection. Axial CT image shows fibrotic bands in the bilateral cheek subcutaneous tissues (arrows).

neous tissues that can present with swelling. This complication is mainly encountered with long-term and permanent fillers, such as silicone, and is predisposed by underlying inflammatory diseases, such allergies, as well as regional infectious processes, such as dental caries and sinusitis. ${ }^{30,31}$ On imaging, chronic inflammatory reactions can appear as diffuse swelling and enhancement of the tissues surrounding the filler material (Fig 12).

Chronic inflammation and perhaps lymphatic obstruction caused by the filler materials can lead to scar formation. ${ }^{30,32}$ Scarring can develop many years after injection of the filler. ${ }^{27}$ Particularly severe fibrotic reactions have been reported with liquid silicone. ${ }^{30,32,33}$ Scarring related to silicone injection consists of subcutaneous fibrotic masses that can appear as thick bands of soft tissue attenuation on CT (Fig 13). Retraction of the overlying skin can also be observed. This complication is often disfiguring, with limited mobility of the mimetic muscles, and is difficult to treat even via steroid injections and surgical excision. ${ }^{28}$

Foreign-body granulomas are considered rare complications of FDA-approved injectable facial fillers, with incidences ranging from $0.02 \%$ to $1 \%$, and tend to develop several months to years after injection. ${ }^{34,35}$ Silicone oil has a relatively high incidence of foreign-body granuloma formation, though this adverse reaction most commonly results from the use of preparations that are not "medical grade" silicone. ${ }^{13,32,36}$ Several histologic types of foreign-body granulomas can occur, depending on the type of filler agent used, including the classic giant cell granuloma type associated with most new fillers and cystic and macrophagic types associated with liquid silicone. ${ }^{37}$ Consequently the imaging features of foreign-body granulomas are variable, ranging from solid-to-cystic round or ovoid foci with associated irregular microcalcifications or small ringlike or large eggshell calcifications and surrounding fibrosis (Fig 14). ${ }^{38}$ Granulomas can grow to several millimeters. If diagnosed early, the lesions can regress with corticosteroid injections. ${ }^{34}$ Otherwise, foreign-body granulomas can become disfiguring and are difficult to treat surgically.

Disclosures: Charles Schatz-UNRELATED: Employment: Beverly Radiology Medical Group, Comments: I am a full-time diagnostic radiologist specializing in head and

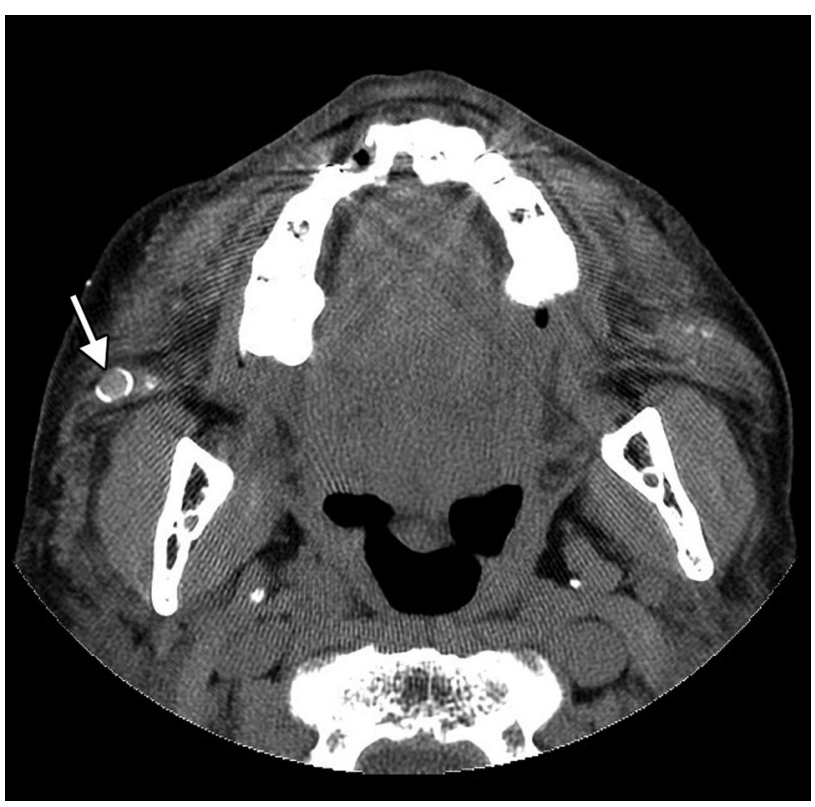

FIG 14. Foreign-body granuloma. The patient underwent silicone injection 50 years before. Axial CT image shows a nodule with eggshell calcification in the right cheek (arrow).

neck radiology for this company, Payment for Lectures (including service on Speakers Bureau): I gave a lecture at the 2012 Los Angeles Radiological Society meeting entitled "Cosmesis: The Good, The Bad, and the Ugly." I was given a $\$ 400$ honorarium; I was an invited speaker, Travel/Accommodations/Meeting Expenses Unrelated to Activities Listed: Two-night hotel stay at the aforementioned meeting.

\section{REFERENCES}

1. Kontis TC, Rivkin A. The history of injectable facial fillers. Facial Plast Surg 2009;25:67-72

2. Ridenour B, Kontis TC. Injectable calcium hydroxylapatite microspheres (Radiesse). Facial Plast Surg 2009;25:100-05

3. Schatz CJ, Ginat DT. Imaging of facial cosmesis. In: Ginat DT, Westesson PL, eds. Atlas of Postsurgical Neuroradiology. Berlin, Germany: Springer-Verlag; 2012. In press

4. Feeney JN, Fox JJ, Akhurst T. Radiological impact of the use of calcium hydroxylapatite dermal fillers. Clin Radiol 2009;64:897-902

5. Carruthers A, Liebeskind M, Carruthers J, et al. Radiographic and computed tomographic studies of calcium hydroxylapatite for treatment of HIV-associated facial lipoatrophy and correction of nasolabial folds. Dermatol Surg 2008;34(suppl 1):S78-84

6. Bass LS, Smith S, Busso M, et al. Calcium hydroxylapatite (Radiesse) for treatment of nasolabial folds: long-term safety and efficacy results. Aesthet Surg J 2010;30:235-38

7. Saray A. Porcine dermal collagen (Permacol) for facial contour augmentation: preliminary report. Aesthetic Plast Surg 2003;27:368-75

8. Fagien S, Elson ML. Facial soft-tissue augmentation with allogeneic human tissue collagen matrix (Dermalogen and Dermaplant). Clin Plast Surg 2001;2:63-81

9. Homicz MR, Watson D. Review of injectable materials for soft tissue augmentation. Facial Plast Surg 2004;20:21-29

10. Lemperle G, Romano JJ, Busso M. Soft tissue augmentation with artecoll: 10-year history, indications, techniques, and complications. Dermatol Surg 2003;29:573-87, discussion 587

11. Duffy DM. Liquid silicone for soft tissue augmentation. Dermatol Surg 2005;31:1530-41

12. Mathews VP, Elster AD, Barker PB, et al. Intraocular silicone oil: in vitro and in vivo MR and CT characteristics. AJNR Am J Neuroradiol 1994;15:343-47

13. Chasan PE. The history of injectable silicone fluids for soft-tissue augmentation. Reconstr Surg 2007;120:2034-40, discussion 2041-43 
14. Sherris DA, Larrabee WF Jr. Expanded polytetrafluoroethylene augmentation of the lower face. Laryngoscope 1996;106:658-63

15. Cisneros JL, Singla R. Intradermal augmentation with expanded polytetrafluoroethylene (Gore-Tex) for facial lines and wrinkles. $J$ Dermatol Surg Oncol 1993;19:539-42

16. Kumar VA, Lewin JS, Ginsberg LE. CT assessment of vocal cord medialization. AJNR Am J Neuroradiol 2006;27:1643-46

17. Carruthers J, Carruthers A. Hyaluronic acid gel in skin rejuvenation. J Drugs Dermatol 2006;5:959-64

18. Smith KC. Reversible vs. nonreversible fillers in facial aesthetics: concerns and considerations. Dermatol Online J 2008;14:3

19. Gensanne D, Josse G, Schmitt AM, et al. In vivo visualization of hyaluronic acid injection by high spatial resolution $\mathrm{T} 2$ parametric magnetic resonance images. Skin Res Technol 2007;13:385-89

20. Lupo MP. Hyaluronic acid fillers in facial rejuvenation. Semin $\mathrm{Cu}$ tan Med Surg 2006;25:122-26

21. Fitzgerald R, Vleggaar D. Facial volume restoration of the aging face with poly-1-lactic acid. Dermatol Ther 2011;24:2-27

22. Sterling JB, Hanke CW. Poly-L-lactic acid as a facial filler. Skin Therapy Lett 2005;10:9-11

23. Perry CM. Poly-L-lactic acid. Am J Clin Dermatol 2004;5:361-66, discussion 367-68

24. Lacombe V. Sculptra: a stimulatory filler. Facial Plast Surg 2009;25:95-99

25. Teo SY, Wang SC. Radiologic features of polyacrylamide gel mammoplasty. AJR Am J Roentgenol 2008;191:W89-95

26. Verpaele A, Strand A. Restylane SubQ, a non-animal stabilized hyaluronic acid gel for soft tissue augmentation of the mid-and lower face. Aesthet Surg J 2006;26:S10-17

27. Reda-Lari A. Augmentation of the malar area with polyacrylamide hydrogel: experience with more than 1300 patients. Aesthet Surg $J$ 2008;28:131-38
28. Sturm LP, Cooter RD, Mutimer KL, et al. A systematic review of dermal fillers for age-related lines and wrinkles. ANZ J Surg 2011;81:9-17

29. Judodihardjo H, Dykes P. Objective and subjective measurements of cutaneous inflammation after a novel hyaluronic acid injection. Dermatol Surg 2008;34(suppl 1):S110-14

30. Rapaport MJ, Vinnik C, Zarem H. Injectable silicone: cause of facial nodules, cellulitis, ulceration, and migration. Aesthetic Plast Surg 1996;20:267-76

31. Narins RS, Beer K. Liquid injectable silicone: a review of its history, immunology, technical considerations, complications, and potential. Plast Reconstr Surg 2006;118(3 suppl):77S-84S

32. Mastruserio M, Pesqueira MJ, Cobb MW. Severe granulomatous reaction and facial ulceration occurring after subcutaneous silicone injection. J Am Acad Dermatol 1996;34:849-52

33. Raszewski R, Guyuron B, Lash RH, et al. A severe fibrotic reaction after cosmetic liquid silicone injection. J Craniomaxillofac Surg 1990;18:225-28

34. Lemperle G, Gauthier-Hazan N, Wolters M, et al. Foreign body granulomas after all injectable dermal fillers. Part 1. Possible causes. Plast Reconstr Surg 2009;123:1842-63

35. Lemperle G, Rullan PP, Gauthier-Hazan N. Avoiding and treating dermal filler complications. Plast Reconstr Surg 2006;118(3 suppl):92S-107S

36. Christensen L, Breiting V, Janssen M, et al. Adverse reactions to injectable soft tissue permanent fillers. Aesthetic Plast Surg 2005;29:34-48

37. Lombardi T, Samson J, Plantier F, et al. Orofacial granulomas after injection of cosmetic fillers: histopathologic and clinical study of 11 cases. J Oral Pathol Med 2004;33:115-20

38. Hirsch RJ, Stier M. Complications of soft tissue augmentation. $J$ Drugs Dermatol 2008;7:841-45 